(2) Open Access Full Text Article

\title{
Investigation of insulin resistance in narcoleptic patients: dependent or independent of body mass index?
}

\author{
This article was published in the following Dove Press journal: \\ Neuropsychiatric Disease and Treatment \\ 8 June 2011 \\ Number of times this article has been viewed
}

\author{
Alice Engel ${ }^{1,2}$ \\ Jana Helfrich' \\ Nina Manderscheid' \\ Petra B Musholt ${ }^{3}$ \\ Thomas Forst ${ }^{3}$ \\ Andreas Pfützner ${ }^{3}$ \\ Norbert Dahmen ${ }^{1,2}$ \\ 'Department of Psychiatry, University \\ of Mainz, Germany; ${ }^{2}$ Fachklinik \\ Katzenelnbogen, Katzenelnbogen, \\ Germany; ${ }^{3} \mathrm{KKFE}$, Institute for Clinical \\ Research and Development, Mainz, \\ Germany
}

\begin{abstract}
Background: Narcolepsy is a severe sleep-wake cycle disorder resulting in most cases from a lack of orexin, the energy balance-regulating hormone. Narcoleptic patients have been reported to suffer from an excess morbidity of Type 2 diabetes, even after correction for their often elevated body mass index.
\end{abstract}

Methods: To explore whether narcolepsy is specifically associated with a propensity to develop insulin resistance, we measured fasting glucose, insulin, and intact proinsulin levels in 43 narcoleptic patients and 47 controls matched for body mass index and age. The proinsulin-to-insulin ratio was calculated. Insulin resistance was determined using the homeostatic model assessment method.

Results: Narcoleptic patients did not show elevated insulin resistance parameters.

Conclusion: In contrast with earlier reports, we found no evidence that narcolepsy specifically elevates the risk of insulin resistance (and consequently of type 2 diabetes) independently of body mass index.

Keywords: fasting glucose, insulin, intact proinsulin, narcolepsy, obesity

\section{Introduction}

Narcolepsy is a rare disease that affects approximately $0.05 \%$ of the population in Western countries. It is typically characterized by excessive daytime sleepiness, cataplexy, sleep onset rapid eye movement sleep periods, and the presence of the human leukocyte antigen (HLA) DQB1*0602 allele. ${ }^{1}$ The association between the DQA $1 * 0102 / D Q B 1 * 0602$ alleles and narcolepsy is among the strongest HLA associations in medicine, and suggests an autoimmune pathogenesis of the disorder. ${ }^{2}$ There is evidence that the hypocretin/orexin neurotransmission system is involved in the pathophysiology of narcolepsy. Orexin, a neurotransmitter which is produced by a restricted set of cells located in the hypothalamus, is not only involved in the regulation of sleep but also plays a role in energy expenditure and body weight regulation. It promotes feeding behavior. Food intake leads to decreased activity of orexinergic neurons and lower orexin levels, and fasting leads to an increased orexin level. ${ }^{3-8}$ The role of orexin suggests that hypocretin deficiency in narcoleptic patients should lead to reduced food intake and loss of body weight. ${ }^{5,6}$ Surprisingly, it has been found that narcoleptic patients have higher body mass indices than community-based samples. ${ }^{9-11}$ Moreover, Honda et al reported a prevalence of type 2 diabetes mellitus in six of 48 narcoleptic patients (12.5\%). They concluded that the tendency towards
Correspondence: Alice Engel Department of Psychiatry, University of Mainz, Untere Zahlbacher Straße 8,

55।3| Mainz, Germany

Tel +496131172156

Fax +496I3II76690

Email aliceengel@gmx.net 
diabetes might be independent of body mass index (BMI) because there were no differences in the prevalence between the obese and nonobese narcoleptic patients. Ever since then, it is commonly understood that narcoleptic patients have an increased risk of developing type 2 diabetes. ${ }^{11}$

Recently a research group from Italy conducted a very detailed study on metabolic alterations in narcoleptic patients, including measurement of BMI, waist circumference, blood pressure, daily calorie intake (three-day diary), and biochemical and hormonal parameters (cholesterol, insulin, and leptin, among others). ${ }^{12}$ They found that nine of 14 patients displayed the metabolic syndrome compared with 14 ageand gender-matched patients with idiopathic hypersomnia, of whom none were affected. Although the study was carefully performed, there were several limitations, including a small sample size and especially the fact that both groups were not BMI-matched (patients with narcolepsy $28 \pm 4.4$, patients with idiopathic hypersomnia $24.2 \pm 2.8, P=0.012$ ), because $\mathrm{BMI}$ is one of the greatest influencing factors of the metabolic syndrome besides age. Even individuals in the upper normal weight and slightly overweight BMI range are at increased risk of having the metabolic syndrome. ${ }^{13-16}$

In order to increase the sensitivity and power of our own study we focused on insulin resistance, one of the pathophysiological components of type 2 diabetes and metabolic syndrome. ${ }^{17}$ Many studies have shown that insulin resistance will progress to overt diabetes or metabolic syndrome within only a few years. ${ }^{18-20}$ In insulin resistance, the pancreas compensates for the increased insulin to maintain normal blood glucose levels. However, the intracellular processing capacities may soon become exhausted and incomplete processing of the insulin leads to increased release of intact or partly processed proinsulin. ${ }^{21}$ Once the beta cell secretion fails to maintain glucose control, impaired glucose tolerance and diabetes mellitus are the consequences. ${ }^{22}$ The hyperinsulinemic-euglycemic clamp technique and the intravenous glucose tolerance test are the gold standard methods for measuring insulin sensitivity. ${ }^{23,24}$ Both are very time- and resource-consuming and not suitable for routine clinical use. Therefore, we used a composite of surrogate parameters to assess insulin resistance in our patients by measuring insulin and glucose for calculation of the homeostasis assessment model of insulin resistance (HOMA-IR) $\operatorname{score}^{25}$ in narcoleptic patients and controls matched for age, gender, and BMI. We also determined intact proinsulin to calculate the proinsulin-to-insulin ratio and to determine the prevalence of insulin resistance as described by Pfützner et al. ${ }^{21}$

\section{Methods}

\section{Patients}

The study design was approved by the ethics committee of the Medical Association of Rhineland-Palatinate that is responsible for all clinical studies performed at the University of Mainz. The study was conducted in accordance with all relevant ethical and legal regulations. All participants gave their written informed consent prior to study entry. A total of 43 patients (22 males and 21 females) with a diagnosis of narcolepsy according to the Diagnostic and Statistical Manual of Mental Disorders, Fourth Edition (DSM-IV) and the International Classification of Sleep Disorders (ICSD) criteria were enrolled into this cross-sectional investigation. ${ }^{26}$ Patients were all unrelated and were either referred from the Department of Psychiatry, University Hospital Mainz, or recruited with the help of the Deutsche NarkolepsieGesellschaft, a nationwide German patient organization. Narcolepsy symptoms, severity and frequency of symptoms, and total duration of various aspects of the symptomatology were assessed by unstructured and structured clinical interviews, including the Stanford Center for Narcolepsy Sleep Inventory (www.med.stanford.edu/school/Psychiatry/ narcolepsy/sleepinventory.pdf). In accordance with the ICSD II for the diagnosis of narcolepsy, patients who had not undergone polysomnographic examination were only admitted to the study when unambiguous cataplexies, additional rapid eye movement-associated symptoms, and severe daytime sleepiness with recurrent daytime naps or lapses into sleep for at least three months were reported. To exclude symptomatic narcolepsy, the medical history was assessed and a neurologic examination was performed.

As a control group, 47 healthy unrelated volunteers (22 males and 25 females) matched for age and gender were recruited. All controls had undergone an oral glucose tolerance test to exclude diabetes mellitus. Further exclusion criteria were pregnancy, multiple allergies, drug abuse, or any other psychiatric disorders limiting the capacity to consent. All participants were of Caucasian origin.

\section{Measurements}

Glucose levels were determined using a standard reference laboratory method (glucose oxidase method) according to the manufacturer's instructions (Super GL, RLT, Möhnesee, Germany). Insulin and intact proinsulin were determined as previously described ${ }^{27}$ by means of specific immunoassays (MLT insulin [intra-assay and interassay coefficients of variation $3.8 \%$ and $2.3 \%$, respectively, reference range $<30 \mu \mathrm{U} / \mathrm{mL}$ ] and LINCO Intact Proinsulin [intra-assay and interassay 
coefficients of variation $5.2 \%$ and $8.6 \%$, respectively, reference range $<10 \mathrm{pmol} / \mathrm{L}$ ], LINCO Research Inc, St Charles, MO).

The proinsulin-to-insulin ratio was calculated by dividing the concentration of proinsulin ( $\mathrm{pmol} / \mathrm{L}$ ) by insulin (converted from $\mu \mathrm{U} / \mathrm{mL}$ into $\mathrm{pmol} / \mathrm{L}$ ). Insulin resistance was diagnosed based on prevalence of elevated fasting intact proinsulin ${ }^{21,28}$ or elevated fasting HOMA-IR score calculation. ${ }^{25}$ The estimate of insulin resistance by HOMA-IR score was calculated as fasting serum insulin $(\mu \mathrm{U} / \mathrm{mL}) \times$ fasting plasma glucose $(\mathrm{mg} / \mathrm{dL}) / 405$. As described by Hedblad et al patients with HOMA scores exceeding the 75 th percentile of a nondiabetic patient population (ie, 2.0) were considered to have insulin resistance. ${ }^{29}$

\section{Statistical analysis}

Statistical analysis was performed using descriptive statistics and appropriate parametric and nonparametric tests. The Kolmogorov-Smirnov test was used to ensure that the studied variables did not significantly differ from a normal distribution. The Mann-Whitney $U$ test was used to compare rank sums. For the comparison of proportions, the Chi-square test was used. Descriptive results of continuous variables were expressed as the median and interquartile range for the nonGaussian variables. All tests were two-sided. Linear regression was used to analyze the impact of BMI and age on the parameters of insulin resistance. Results with $P$ values $<0.05$ were considered to be statistically significant. All calculations were conducted with SPSS software (version 15.0 for Windows, SPSS Inc, Chicago, IL).

\section{Results}

A general characterization of patients and controls is given in Table 1.

\section{Fasting glucose}

Median fasting plasma glucose was significantly lower in the narcoleptic patients as compared with the healthy controls (narcoleptic patients 85.0 [76.0-95.0] $\mathrm{mg} / \mathrm{dL}$, controls 96.5 [87.5-102.8] mg/dL, $P<0.001)$. The differences were also conserved in the gender subgroups (male narcoleptic patients 86.0 [81.3-103.5] mg/dL; controls 101.0 [93.8-108.3] mg/dL, $P=0.031$; female narcoleptic patients 78.0 [72.5-88.0] mg/dL; controls 93.3 [85.3-93.3] $\mathrm{mg} / \mathrm{dL}, P=0.001)$. One control and one narcoleptic patient had fasting glucose values above $>126 \mathrm{mg} / \mathrm{dL}(P=0.987)$. Fasting glucose correlated with $\mathrm{BMI}$ in narcoleptic patients $(\mathrm{r}=0.384, P=0.011)$ and controls $(\mathrm{r}=0.349, P=0.020)$ and with age in the narcoleptic group $(\mathrm{r}=0.339, P=0.026)$, but not in the control group $(\mathrm{r}=0.247, P=0.106)$.
Table I Characterization of patients and controls

\begin{tabular}{llll}
\hline Characteristics & $\begin{array}{l}\text { Narcoleptic } \\
\text { patients }\end{array}$ & Controls & P value \\
\hline $\mathrm{n}$ & 43 & 47 & \\
Males & $22(51.2 \%)$ & $22(46.8 \%)$ & \\
Females & $21(48.9 \%)$ & $25(53.2 \%)$ & \\
Age (years) & $49.2 \pm 16.6$ & $50.6 \pm 16.3$ & 0.678 \\
(Males) & $54.5 \pm 15.3$ & $55.1 \pm 15.3$ & 0.891 \\
(Females) & $43.7 \pm 16.5$ & $46.7 \pm 16.5$ & 0.535 \\
BMI (kg/m²) & $30.2 \pm 6.1$ & $31.0 \pm 5.2$ & 0.505 \\
(Males) & $31.4 \pm 5.2$ & $32.4 \pm 4.0$ & $0.48 I$ \\
(Females) & $28.8 \pm 6.8$ & $29.7 \pm 5.8$ & 0.655 \\
HLA DRI5 positive & $38(88.4 \%)$ & n.a. & \\
(Males) & $20(90.9 \%)$ & & \\
(Females) & $18(85.7 \%)$ & & \\
HLA DRI5 negative & $5(11.6 \%)$ & & \\
(Males) & $2(9.1 \%)$ & & \\
(Females) & $3(14.3 \%)$ & & \\
Duration of & $29.8 \pm 17.2$ & & \\
narcolepsy (years) & & & \\
Age of onset (years) & $16.0(12.0-23.0)$ & \\
ESS score & $18.14 \pm 3.68$ & & \\
\hline Abbrevatons BMI & &
\end{tabular}

Abbreviations: BMI, body mass index; HLA, human leukocyte antigen; ESS, Epworth Sleepiness score; n.a., not asked.

\section{Insulin}

Median insulin levels were 7.58 (5.6-11.6) $\mu \mathrm{U} / \mathrm{mL}$ in narcoleptic patients and $10.14(6.9-13.7) \mu \mathrm{U} / \mathrm{mL}$ in controls $(P=0.185)$. Accordingly, median insulin levels in narcoleptic females $(6.50$ [5.5-10.0] $\mu \mathrm{U} / \mathrm{mL})$ were not different from female controls $(8.06[4.5-10.3] \mu \mathrm{U} / \mathrm{mL}, P=0.680)$ and median insulin levels in male narcoleptic patients were similar to those in male controls (narcoleptic patients 9.40 [6.1-17.0] $\mu \mathrm{U} / \mathrm{mL}$; controls 11.20 [10.1-15.9] $\mu \mathrm{U} / \mathrm{mL}$, $P=0.205)$. Five narcoleptic patients and four controls had values above $17 \mu \mathrm{U} / \mathrm{mL}(P=0.698)$. Insulin levels did correlate with $\mathrm{BMI}$ in both diagnostic groups (narcoleptic patients: $r=0.413, P=0.006$; controls $r=0.522, P<0.001)$ and did not correlate with age (narcoleptic patients: $\mathrm{r}=0.077$, $P=0.622$; controls $\mathrm{r}=0.172, P=0.266)$.

\section{Intact proinsulin}

Median intact proinsulin values were slightly higher in controls than in narcoleptic patients (narcoleptic patients 2.46 [1.3-6.3] pmol/L versus controls 3.82 [2.4-7.1] pmol/L, $P=0.046)$. Intact proinsulin medians were 2.83 (1.9-9.4) $\mathrm{pmol} / \mathrm{L}$ in narcoleptic men and $1.6(1.1-3.4) \mathrm{pmol} / \mathrm{L}$ in narcoleptic women. The corresponding values for the male controls were $5.32(3.8-9.9) \mathrm{pmol} / \mathrm{L}(P=0.060)$ and $2.4(1.6-2.4)$ for the female controls $(P=0.172)$. Five narcoleptic patients and three controls showed intact proinsulin values above $11 \mathrm{pmol} / \mathrm{L}(P=0.382)$, ie, the reference value for stage III 
beta cell dysfunction and insulin resistance. ${ }^{16}$ In both groups, there was a significant correlation between intact proinsulin and BMI (narcoleptic patients: $\mathrm{r}=0.464, P=0.002$; controls $\mathrm{r}=0.485, P=0.001)$. Correlations of proinsulin with age were $\mathrm{r}=0.243$ (narcoleptic patients, $P=0.116$ ) and $\mathrm{r}=0.308$ (controls, $P=0.035$ ). The proinsulin-to-insulin ratio was marginally lower in narcoleptic patients than in the controls (narcoleptic patients 4.31 versus controls 5.35, $P=0.033$ ).

\section{HOMA-IR}

Median HOMA values were 1.51 (1.1-3.1) for narcoleptic patients and $2.68(1.6-3.5)$ for controls $(P=0.048)$. HOMA $>2.5$ were found in 12 patients $(27.9 \%)$ and 23 controls $(52.3 \%, P=0.020)$. Two patients and two controls had HOMA values $>5(P=0.981)$. HOMA correlated with BMI in both diagnostic groups (narcoleptic patients: $\mathrm{r}=0.489, P=0.001$; controls $\mathrm{r}=0.474, P=0.001$ ) but not with age (narcoleptic patients: $\mathrm{r}=0.195, P=0.209$; controls $\mathrm{r}=0.236, P=0.123)$.

\section{Insulin resistance}

Insulin resistance, defined as fasting glucose levels $>126 \mathrm{mg} / \mathrm{dL}$, insulin levels above $17 \mu \mathrm{U} / \mathrm{mL}$, intact proinsulin values above $11 \mathrm{pmol} / \mathrm{L}$, and HOMA values $>5$, was prevalent in one narcoleptic patient $(2.3 \%)$ and not in any controls $(P=0.478)$. Insulin resistance, as defined by a HOMA-IR score $>2.0$ and increased fasting intact proinsulin levels, ${ }^{21}$ was present in four narcoleptic patients $(9.3 \%)$ and three of the healthy control subjects $(6.4 \%, P=0.450)$. A summary of the results is also given in Table 2 . Linear regression analysis with fasting glucose, insulin, intact proinsulin, and HOMA-IR as dependent variables and BMI and age as independent variables showed no impact of BMI on intact proinsulin $(P=0.557)$ but did show an impact on fasting glucose $(P=0.015)$, insulin $(P<0.001)$, and HOMA-IR $(P<0.001)$. No impact of age was found for insulin $(P=0.400)$, intact proinsulin $(P=0.869)$, and HOMA-IR $(P=0.908)$ but did show an impact for fasting glucose $(P=0.016)$. None of the markers were correlated with disease duration (data not shown).

\section{Discussion}

In our study, narcoleptic patients did not show higher fasting blood glucose levels than age- and BMI-matched controls. Also, insulin and intact proinsulin levels were not elevated in the narcoleptic group, nor was the proinsulin-to-insulin ratio, HOMA-IR-levels, or prevalence of insulin resistance. This result is in contrast with the clinical belief that narcolepsy per se and independently from BMI is associated with an increased
Table 2 Glucose levels, insulin, intact proinsulin, proinsulinto-insulin ratio, and homeostasis assessment model of insulin resistance of narcoleptic patients and control subjects, values are given as median (quartiles). Additionally, both groups were split for gender

\begin{tabular}{|c|c|c|c|}
\hline & Narcoleptics & Controls & $P$ value \\
\hline $\begin{array}{l}\text { Fasting glucose } \\
(\mathrm{mg} / \mathrm{dL})\end{array}$ & $85.0(76.0-95.0)$ & $96.5(87.5-102.8)$ & $<0.001$ \\
\hline Males & $86.0(81.3-103.5)$ & $101.0(93.8-108.3)$ & 0.031 \\
\hline Females & $78.0(72.5-88.0)$ & $93.3(85.3-93.3)$ & 0.001 \\
\hline Insulin $(\mu \mathrm{U} / \mathrm{mL})$ & $7.58(5.6-1 \mathrm{I} .6)$ & $10.14(6.9-13.7)$ & 0.185 \\
\hline Males & $9.40(6.1-17.0)$ & $11.20(10.1-15.9)$ & 0.205 \\
\hline Females & $6.50(5.5-10.0)$ & $8.06(4.5-10.3)$ & 0.680 \\
\hline $\begin{array}{l}\text { Intact proinsulin } \\
\text { (pmol/L) }\end{array}$ & $2.46(1.3-6.3)$ & $3.82(2.4-7.1)$ & 0.046 \\
\hline Males & $2.83(1.9-9.4)$ & $5.23(3.8-9.9)$ & 0.060 \\
\hline Females & $1.63(1.1-3.4)$ & $2.38(1.6-2.4)$ & 0.172 \\
\hline $\begin{array}{l}\text { Proinsulin-to- } \\
\text { insulin ratio (\%) }\end{array}$ & $4.31(3.0-7.0)$ & $5.35(4.4-8.1)$ & 0.033 \\
\hline Males & $4.99(3.1-8.8)$ & $6.16(4.8-10.6)$ & 0.250 \\
\hline Females & $3.52(2.4-6.0)$ & $5.07(3.6-6.1)$ & 0.055 \\
\hline HOMA index & I.5I (I.I-3.I) & $2.68(1.6-3.5)$ & 0.048 \\
\hline Males & $2.01(1.3-3.6)$ & $2.96(2.6-3.9)$ & 0.096 \\
\hline Females & I.3 (I.0-2.0) & $1.96(1.0-2.0)$ & 0.264 \\
\hline
\end{tabular}

Abbreviation: HOMA, homeostatic model assessment.

(pre) diabetic metabolic state. Our conclusion is supported by the fact that all controls were examined by an oral glucose tolerance test prior to inclusion in the study and in this way manifest diabetes was excluded from the control group. Therefore, the only potential bias was in favor of an overestimation of potential markers of prediabetes in the narcoleptic patients.

One limitation of the study is that because of the low prevalence of narcolepsy, it was not possible to recruit a strictly representative population sample. Instead, patients were recruited with the support of a patient organization. It has been estimated that a large fraction of narcoleptic patients in the general population are undiagnosed. ${ }^{30}$ This problem is unavoidable when studying rare disorders and is true for most, if not all, published narcolepsy studies. However, we took care not to introduce additional bias by embedding our study in a study of overweight and metabolic parameters with no explicit reference to type 2 diabetes.

A second limitation is the choice of the observation parameters. In particular, no oral glucose tolerance test, intravenous glucose tolerance test, or hyperinsulinemiceuglycemic clamp test were performed in the narcoleptic patients. Although being a very simple, cheap, and convenient parameter (and recommended by the American Diabetes Association), ${ }^{31}$ fasting glucose alone is poorly predictive of insulin resistance and a very crude parameter 
for assessing beta cell function. ${ }^{32-34}$ Fasting glucose also has a poor sensitivity for diabetes diagnosis (40\%-60\%) and may delay the diagnosis of dysglycemia. ${ }^{35}$ Waugh et al found that the majority of patients with impaired glucose tolerance would be missed by assessing only fasting plasma glucose levels. ${ }^{36}$ Nevertheless, elevated fasting glucose levels are predictive for manifest diabetes. . $2,31^{2}$

Although fasting insulin is considered to be a relatively good indicator of insulin resistance among nondiabetic persons, ${ }^{37}$ other studies have revealed that the relationship between insulin resistance measured by an euglycemic clamp and fasting serum insulin level is weak. Insulin levels are less suited to yield a diagnosis in the single patient than to study metabolic tendencies in groups. ${ }^{38,39}$ Intact proinsulin has been shown to be a highly specific indirect marker for insulin resistance. Elevation of intact proinsulin values above the reference range $(>11 \mathrm{pmol} / \mathrm{L})$ shows a very high specificity and a moderate sensitivity as a marker for insulin resistance. ${ }^{21}$ Plasma intact proinsulin concentrations are usually highest in patients with type 2 diabetes, lower in those with normal glucose tolerance, and moderately elevated in patients with impaired glucose tolerance. The results reported by Reaven show that ambient plasma proinsulin concentrations increase as glucose tolerance declines. ${ }^{13}$

In addition, impaired glucose tolerance in type 2 diabetes is often characterized by an increased ratio of proinsulin to insulin. The results reported by Mykkanen et al suggest that an increased intact proinsulin-to-insulin ratio is a marker of defective insulin secretion. ${ }^{40,41}$ While this group considered the proinsulin-to-insulin ratio to be a good marker for impaired beta cell function, Vezzosi et al found that the proinsulin-to-insulin ratio did not result in better diagnostic accuracy than proinsulin levels alone. Because there are no commonly accepted reference ranges set for the ratio, we compared our results with other research papers and found values of $1 \%-16 \%$ described to be physiological. ${ }^{41-44}$

The HOMA method is derived from a mathematical assessment of the interaction between beta cell function and insulin resistance in an idealized model, which is then used to compute steady-state insulin and glucose concentrations. The output of the model is calibrated to give normal beta cell function of $100 \%$ and a normal insulin resistance of 1 . Once this interrelationship is calculated, one can estimate beta cell function and insulin resistance for any pair of fasting plasma glucose and insulin concentrations. The HOMA model has proved to be a reliable clinical and epidemiological instrument to describe the pathophysiology of diabetes, except in the stage of severe beta cell dysfunction leading to proinsulin secretion. ${ }^{25}$
Taken together, the combined measurement of fasting glucose, insulin, and intact proinsulin is a practical and robust way to not only diagnose manifest diabetics but also to characterize prediabetic metabolic states. $^{28}$

In summary, we found no evidence that narcolepsy elevates the risk for prediabetic states of insulin resistance independently of BMI. The fact that the narcoleptic patients had even lower insulin resistance parameters than the controls might give the wrong impression that narcoleptic patients have a smaller risk of developing type 2 diabetes. This effect still needs to be elucidated. Clinically, type 2 diabetes still remains a challenge in narcoleptic patients because of the association of narcolepsy with an elevated BMI.

\section{Acknowledgments}

We greatly appreciate the work of Mirjam Löbig, Maja Knezovic, and the team at the IKFE laboratory in performing fasting glucose, insulin, and intact proinsulin determinations. We also wish to thank WE Hitzler and A Jung from the University of Mainz Transfusion Center for HLA typing. This work contains parts of the doctoral thesis of AE, and was supported by DFG DA 370/4-1.

\section{Disclosure}

The authors report no conflicts of interest in this work.

\section{References}

1. Aldrich MS. The clinical spectrum of narcolepsy and idiopathic hypersomnia. Neurology. 1996;46(2):393-401.

2. Black JL 3rd. Narcolepsy: A review of evidence for autoimmune diathesis. Int Rev Psychiatry. 2005;17(6):461-469.

3. Chemelli RM, Willie JT, Sinton CM, et al. Narcolepsy in orexin knockout mice: Molecular genetics of sleep regulation. Cell. 1999;98(4): 437-451.

4. Lin L, Faraco J, Li R, et al. The sleep disorder canine narcolepsy is caused by a mutation in the hypocretin (orexin) receptor 2 gene. Cell. 1999;98(3):365-376.

5. Sakurai T. Orexins and orexin receptors: Implication in feeding behavior. Regul Pept. 1999;85(1):25-30.

6. Siegel JM. Narcolepsy: A key role for hypocretins (orexins). Cell. 1999;98(4):409-412.

7. Williams G, Bing C, Cai XJ, Harrold JA, King PJ, Liu XH. The hypothalamus and the control of energy homeostasis: Different circuits, different purposes. Physiol Behav. 2001;74(4-5):683-701.

8. Shiraishi T, Oomura Y, Sasaki K, Wayner MJ. Effects of leptin and orexin-A on food intake and feeding related hypothalamic neurons Physiol Behav. 2000;71(3-4):251-261.

9. Schuld A, Beitinger PA, Dalal M, et al. Increased body mass index (BMI) in male narcoleptic patients, but not in HLA-DR2-positive healthy male volunteers. Sleep Med. 2002;3(4):335-339.

10. Dahmen N, Bierbrauer J, Kasten M. Increased prevalence of obesity in narcoleptic patients and relatives. Eur Arch Psychiatry Clin Neurosci. 2001;251(2):85-89.

11. Honda $Y$, Doi $Y$, Ninomiya R, Ninomiya C. Increased frequency of non-insulin-dependent diabetes mellitus among narcoleptic patients. Sleep. 1986;9(1 Pt 2):254-259. 
12. Poli F, Plazzi G, Di Dalmazi G, et al. Body mass index-independent metabolic alterations in narcolepsy with cataplexy. Sleep. 2009;32(11): 1491-1497.

13. Reaven GM. Banting lecture 1988. Role of insulin resistance in human disease. Diabetes. 1988;37(12):1595-1607.

14. Esteghamati A, Khalilzadeh O, Anvari M, Ahadi MS, Abbasi M, Rashidi A. Metabolic syndrome and insulin resistance significantly correlate with body mass index. Arch Med Res. 2008;39(8): 803-808.

15. Cornier MA, Dabelea D, Hernandez TL, et al. The metabolic syndrome. Endocr Rev. 2008;29(7):777-822.

16. St-Onge MP, Janssen I, Heymsfield SB. Metabolic syndrome in normal-weight Americans: New definition of the metabolically obese, normal-weight individual. Diabetes Care. 2004;27(9):2222-2228.

17. Ioannidis I. The road from obesity to type 2 diabetes. Angiology. 2008; 59(2 Suppl):39S-43S.

18. Lann D, LeRoith D. Insulin resistance as the underlying cause for the metabolic syndrome. Med Clin North Am. 2007;91(6):1063-1077.

19. Cowie CC, Rust KF, Byrd-Holt DD, et al. Prevalence of diabetes and impaired fasting glucose in adults in the US population: National Health And Nutrition Examination Survey 1999-2002. Diabetes Care. 2006;29(6):1263-1268.

20. Knowler WC, Barrett-Connor E, Fowler SE, et al. Reduction in the incidence of type 2 diabetes with lifestyle intervention or metformin. N Engl J Med. 2002;346(6):393-403.

21. Pfützner A, Kunt T, Hohberg C, et al. Fasting intact proinsulin is a highly specific predictor of insulin resistance in type 2 diabetes. Diabetes Care. 2004;27(3):682-687.

22. DeFronzo RA. Pathogenesis of type 2 (non-insulin dependent) diabetes mellitus: A balanced overview. Diabetologia. 1992;35(4):389-397.

23. Heine RJ, Home PD, Poncher M, et al. A comparison of 3 methods for assessing insulin sensitivity in subjects with normal and abnormal glucose tolerance. Diabetes Res. 1985;2(3):113-120.

24. Bergman RN. Lilly lecture 1989. Toward physiological understanding of glucose tolerance. Minimal-model approach. Diabetes. 1989;38(12): 1512-1527.

25. Matthews DR, Hosker JP, Rudenski AS, Naylor BA, Treacher DF, Turner RC. Homeostasis model assessment: Insulin resistance and betacell function from fasting plasma glucose and insulin concentrations in man. Diabetologia. 1985;28(7):412-419.

26. American Academy of Sleep Medicine. The International Classification of Sleep Disorders. Diagnostic and Coding Manual. 2nd ed. American Academy of Sleep Medicine: Westchester, IL; 2005.

27. Pfützner A, Kunt T, Langenfeld M, Lobig M, Knesovic M, Forst T. Clinical and laboratory evaluation of specific chemiluminescence assays for intact and total proinsulin. Clin Chem Lab Med. 2003;41(9): $1234-1238$

28. Pfützner A, Kann $\mathrm{PH}$, Pfutzner $\mathrm{AH}$, et al. Intact and total proinsulin: New aspects for diagnosis and treatment of type 2 diabetes mellitus and insulin resistance. Clin Lab. 2004;50(9-10):567-573.
29. Hedblad B, Nilsson P, Janzon L, Berglund G. Relation between insulin resistance and carotid intima-media thickness and stenosis in non-diabetic subjects. Results from a cross-sectional study in Malmo, Sweden. Diabet Med. 2000;17(4):299-307.

30. Morrish E, King MA, Smith IE, Shneerson JM. Factors associated with a delay in the diagnosis of narcolepsy. Sleep Med. 2004;5(1):37-41.

31. Nathan DM, Davidson MB, DeFronzo RA, et al. Impaired fasting glucose and impaired glucose tolerance: Implications for care. Diabetes Care. 2007;30(3):753-759.

32. Tabaei BP, Engelgau MM, Herman WH. A multivariate logistic regression equation to screen for dysglycaemia: Development and validation. Diabet Med. 2005;22(5):599-605.

33. Hanson RL, Pratley RE, Bogardus C, et al. Evaluation of simple indices of insulin sensitivity and insulin secretion for use in epidemiologic studies. Am J Epidemiol. 2000;151(2):190-198.

34. Muniyappa R, Lee S, Chen H, Quon MJ. Current approaches for assessing insulin sensitivity and resistance in vivo: Advantages, limitations, and appropriate usage. Am J Physiol Endocrinol Metab. 2008;294(1):E15-E26.

35. Engelgau MM, Narayan KM, Herman WH. Screening for type 2 diabetes. Diabetes Care. 2000;23(10):1563-1580.

36. Waugh N, Scotland G, McNamee P, et al. Screening for type 2 diabetes: Literature review and economic modelling. Health Technol Assess. 2007;11(17):1-125.

37. Haffner SM, Miettinen H, Gaskill SP, Stern MP. Decreased insulin secretion and increased insulin resistance are independently related to the 7-year risk of NIDDM in Mexican-Americans. Diabetes. 1995;44(12):1386-1391.

38. Laakso M. How good a marker is insulin level for insulin resistance? Am J Epidemiol. 1993;137(9):959-965.

39. Samaras K, McElduff A, Twigg SM, et al. Insulin levels in insulin resistance: Phantom of the metabolic opera? Med J Aust. 2006;185(3): 159-161.

40. Mykkänen L, Haffner SM, Hales CN, Ronnemaa T, Laakso M. The relation of proinsulin, insulin, and proinsulin-to-insulin ratio to insulin sensitivity and acute insulin response in normoglycemic subjects. Diabetes. 1997;46(12):1990-1995.

41. Mykkänen L, Zaccaro DJ, Hales CN, Festa A, Haffner SM. The relation of proinsulin and insulin to insulin sensitivity and acute insulin response in subjects with newly diagnosed type II diabetes: The Insulin Resistance Atherosclerosis Study. Diabetologia. 1999;42(9):1060-1066.

42. Vezzosi D, Bennet A, Fauvel J, Caron P. Insulin, C-peptide and proinsulin for the biochemical diagnosis of hypoglycaemia related to endogenous hyperinsulinism. Eur J Endocrinol. 2007;157(1):75-83.

43. Laedtke T, Kjems L, Porksen N, et al. Overnight inhibition of insulin secretion restores pulsatility and proinsulin/insulin ratio in type 2 diabetes. Am J Physiol Endocrinol Metab. 2000;279(3):E520-E528.

44. Wang PW, Abbasi F, Carantoni M, Chen YD, Azhar S, Reaven GM. Insulin resistance does not change the ratio of proinsulin to insulin in normal volunteers. J Clin Endocrinol Metab. 1997;82(10):3221-3224.
Neuropsychiatric Disease and Treatment

\section{Publish your work in this journal}

Neuropsychiatric Disease and Treatment is an international, peerreviewed journal of clinical therapeutics and pharmacology focusing on concise rapid reporting of clinical or pre-clinical studies on a range of neuropsychiatric and neurological disorders. This journal is indexed on PubMed Central, the 'PsycINFO' database and CAS, and is the official

\section{Dovepress}

journal of The International Neuropsychiatric Association (INA). The manuscript management system is completely online and includes a very quick and fair peer-review system, which is all easy to use. Visit http://www.dovepress.com/testimonials.php to read real quotes from published authors. 